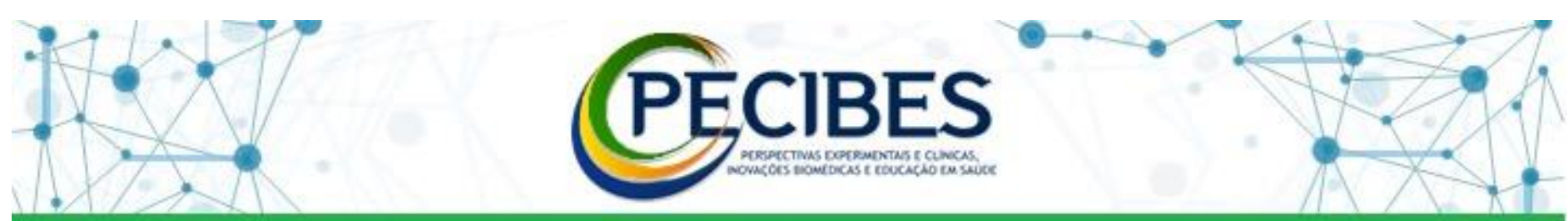

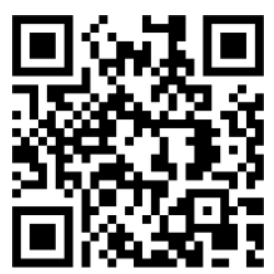

http://www.seer.ufms.br/inde x.php/pecibes/index

\begin{abstract}
* Autor correspondente: Sidney Afonso Sobrinho Junior

Universidade Federal de Mato Grosso

do Sul - UFMS.

E-mail do autor: sidney.junior@ufms.br
\end{abstract}

Descritores: Smartphone. Teste de caminhada Equilíbrio postural. Comportamento

Multitarefa

Key-words: Smartphone. Walk test. Postural balance.Multitasking Behavior. Palabras-clave: Smartphone. Prueba de passo. Equilíbrio postural. Comportamento multitarefa..

\section{Impacto do uso do smartphone como dupla-tarefa à atividade de caminhada: relatos preliminares}

Dual task cost of using smartphone while walking: preliminary reports

Sidney Afonso Sobrinho Junior ${ }^{1}$, Carolina Leonel da Silva Carvalho ${ }^{2}$, Raissa de Sousa Camelo Lima $^{2}$, Gustavo Christofoletti ${ }^{4}$

1. Fisioterapeuta, aluno de mestrado do Programa de Pós-Graduação em Ciências do Movimento, Universidade Federal de Mato Grosso do Sul, Campo Grande, MS, Brasil.

2. Aluna do curso de graduação em Fisioterapia, Universidade Federal de Mato Grosso do Sul, Campo Grande, MS, Brasil.

3. Orientador do Programa de Pós-Graduação em Ciências do Movimento, Universidade Federal de Mato Grosso do Sul, Campo Grande, MS, Brasil.

Eixo Temático: Atenção Multiprofissional em Atividade física, Reabilitação e Desempenho Físico-Funcional

Resumo

Os aparelhos smartphone fazem parte da nossa rotina. Hoje em dia é comum ver pessoas acessando o smartphone enquanto realizam diversas atividades do dia-a-dia. O objetivo deste estudo foi verificar o impacto do uso do smartphone sobre o equilíbrio de adultos jovens quando realizado simultâneo à atividade de caminhada. Este trabalho apresenta

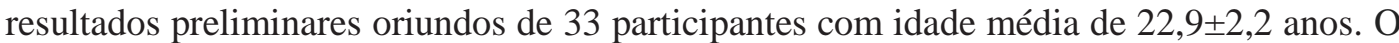
presente estudo foi aprovado pelo Comitê de Ética em Pesquisa (CEP/ UFMS), sob CAAE 47951121.2.0000.0021. Os participantes foram submetidos a atividades com e sem o uso de smartphone durante atividade motora do teste Timed Up and Go. A atividade com o aparelho envolveu tanto a tarefa de digitação de mensagens quanto a atividade de atender uma ligação telefônica. Com objetivo de verificar o impacto do fator ambiente, as coletas de dados foram realizadas em ambiente controlado (laboratório) e não-controlado (rua pública com distratores reais)Testes de análise múltipla de variância para medidas repetidas foram realizadas para verificar o impacto dos fatores tarefa (com e sem o uso do smartphone) e ambiente (laboratório e rua pública). Significância estatística foi estipulada em 5\%. Os resultados apontaram maio efeito da dupla-tarefa com smartphone na atividade de digitação quando comparada à atividade d conversação ou à atividade sem celular. $\mathrm{O}$ uso do smartphone afetou a mobilidade do participantes tanto na atividade realizada em ambiente interno ( $\mathrm{p}=0,001$, tamanho do efeit de 0,691 e poder de 99,9\%) quanto em ambiente externo ( $\mathrm{p}=0,001$, tamanho do efeito d 0,381 e poder de 99,9\%). Em conclusão, os resultados apontaram impacto considerável do uso do smartphone simultâneo à atividade de caminhada. $\mathrm{O}$ tamanho efeito maior $\mathrm{n}$ ambient controlado pode indicar que o participante foque mais na atividade do smartphone no ambiente interno e mais na atividade motora de caminhada no ambienteexterno. 